\title{
ASO Visual Abstract: Muscularity Defined by the Combination of Muscle Quantity and Quality is Closely Related to Both Liver Hypertrophy and Postoperative Outcomes Following Portal Vein Embolization in Cancer Patients
}

\author{
Siyuan Yao, $\mathrm{PhD}^{1}$, Naoko Kamo, $\mathrm{PhD}^{1}$, Kojiro Taura, $\mathrm{PhD}^{1}$, Yosuke Miyachi, $\mathbf{M D}^{1,2}$, Sena Iwamura, $\mathrm{MD}^{1}$, \\ Masaaki Hirata, $\mathrm{MD}^{1}$, Toshimi Kaido, $\mathrm{PhD}^{2}$, and Shinji Uemoto, $\mathbf{P h D}^{1,3}$ \\ ${ }^{1}$ Department of Surgery, Graduate School of Medicine, Kyoto University, Kyoto, Japan; ${ }^{2}$ Department of \\ Gastroenterological and General Surgery, St. Luke's International Hospital, Tokyo, Japan; ${ }^{3}$ Shiga University of Medical \\ Science, Shiga, Japan
}

Patients with high muscularity showed better hypertrophy after PVE and better functional recovery after major hepatectomy.

Low muscularity was an independent risk factor for poor hypertrophy after PVE and posthepatectomy liver failure (h ttps://doi.org/10.1245/s10434-021-10525-w).
Supplementary Information The online version contains supplementary material available at https://doi.org/10.1245/s10434021-10647-1.

DISCLOSURES The authors declare that they have no conflicts of interest related to this article.

Publisher's Note Springer Nature remains neutral with regard to jurisdictional claims in published maps and institutional affiliations.

(C) Society of Surgical Oncology 2021

Published Online: 26 August 2021

S. Yao, $\mathrm{PhD}$

e-mail: siyuan@kuhp.kyoto-u.ac.jp 